\title{
Public Administration Research in Mainland China: An Update
}

Min-Hyu Kim, Huafang Li, Marc Holzer \& Menghong Zhang

Min-Hyu Kim is an assistant professor at the School of Public Affairs, Arizona State UniversityHainan, Haikou City, Hainan, China.

Huafang Li is an assistant professor at the School of Public, Nonprofit and Health Administration, Grand Valley State University, Grand Rapids, MI, USA.

Marc Holzer is a distinguished professor at the Institute for Public Service, Suffolk University, Boston, MA, USA.

Menghong Zhang is an associate professor of the Master of Public Administration program, Gannon University, Erie, PA, USA.

Please cite as Kim, M.-H., Li, H., Holzer, M., \& Zhang, M. (2020). Public Administration Research in Mainland China: An Update. PUBLIC: ESADE Center for Public Governance (ESADEgov) e-Bulletin, 38. https://doi.org/10.31219/osf.io/7brjd 
For the first three decades of the People's Republic of China (1949-1979), China was regarded as a very closed society (Zhang, 2006). The term "closed society" suggests that during this time period China did not often enter into dialogue with the outside world in terms of political, economic, cultural and social issues, etc. Nevertheless, China was heavily influenced by the former Soviet Union in terms of its governance, and adopted the command economy in particular. Over the most recent four decades (1979-2019) enormous changes have occurred in China not only in terms of its rapid and miraculous economic growth, but also for its significant progress in governance, in which public administration has played an indispensable role. Therefore, it is intriguing to understand the history and current status of public administration research in China, as well as implications for scholars and practitioners.

This short paper contributes to filling this knowledge gap. It briefly reviews the intellectual history of public administration in China. It summarizes the findings of public administration research in mainland China in English-language journals (Kim et al., 2019a, b); with the study of a few recent publications (e.g., Chen, 2019; Lan, 2019; Liu, 2019; Zhang, 2019) by leading Chinese scholars in the area, this short paper updates, for scholars and practitioners, the conclusions and implications of public administration research pertaining to mainland China.

\section{Relevance of studying Chinese public administration}

China's economy is the world's second largest by nominal GDP, the largest manufacturing economy in the world, and the largest exporter of goods in the world (IMF, 2019). China is the largest trading nation in the world, and plays a most important role in international trade. Equally impressive is the rapid development of China's public administration sector. Thus, studies of global comparative public administration, including the PRC, are meaningful and may generate important findings. Comparative public administration is an inevitable dimension when we consider the way in which globalization has transformed the roles of government (Holzer and Kasymova, 2012). In this sense, Jreisat (2005) argues that both the national and international environments need to be considered when studying particular administrative reforms.

\section{Intellectual history of public administration in China}

China has a history of civilization dating back approximately 5,000 years, to the period of Three Sovereigns and Five Emperors. As such, China is one of the world's oldest continuous civilizations. After Qin Shi Huang united China in 221 BC, successive dynasties in Chinese history continually developed bureaucratic systems that enabled the Emperor of China to control such a large territory. The Qin Dynasty (221-206 BC) established the first centralized Chinese bureaucratic system, and thus created the need to staff the administrative machinery. The Sui Dynasty (581-618) expanded this Han system, adopted a civil service system and applied it more systematically as a method of official recruitment. The essence of this civil service system was to recruit the "best and brightest" into the government according to their merits, demonstrated by their test scores rather than their blood linkage. 
The ancient Chinese civil service system continued for 1,300 years, from its origin during the Sui Dynasty in 605 to its abolition near the end of the Qing Dynasty in 1905, before the fall of the Qing in 1911 (Roberts, 1993). The United Kingdom built its own civil service system in the middle of the 19th century, and the United States started a similar one by the end of the 19th century based on the ancient Chinese civil service system.

In 2002, the recruits to the first group of 24 MPA programs in the People's Republic of China (PRC) included public and nonprofit employees. To date, 243 universities have been authorized to offer MPA programs by the Chinese government (National MPA Education Steering Committee, 2020). This rapid growth of MPA programs in China reflects an urgent demand for talented public employees to deal with increasingly complicated governance issues in a rapidly transitioning society.

\section{Findings of public administration research in mainland China}

We summarize the findings of public administration research in mainland China in Englishlanguage journals through a recent study (Kim et al., 2019a). The authors conducted an analysis of 346 articles related to Chinese public administration in the top 25 English-language public administration journals worldwide from 1996 to 2016. Our findings are that:

- Only one article was published in 1996 whereas 43 articles were published in 2016. Since 2011, at least 20 articles related to China have been published annually. This result suggests an increasing interest in studying public administration in China.

- Authors' origins: 85 from the United States, 298 from mainland China, 127 from Hong Kong, and 26 from Australia. These results suggest that Chinese public administration has become an intriguing and important topic for many scholars outside of China.

- Research topics: $283(81.8 \%$ ) covered mainland China, while $63(18.2 \%)$ concerned comparative studies. One way to interpret the findings is that academics find it interesting to study Chinese public administration itself as it provides meaningful implications for the United States and other countries.

- The analyses of the research topics showed that 94 articles addressed organization theory, such as administrative reform. There were 47 on finance and budgeting, 46 on social welfare, 34 on public policy, 20 on performance management, and 19 on the environment. The results also showed that the articles on Chinese public administration focused primarily on traditional public management areas.

- This study also investigated the research methods used in studies of Chinese public administration. Some 217 articles (62.7\% ) used qualitative methods, while 117 (33.8\% ) chose quantitative methods. Only twelve (3.5\%) studies applied mixed methods.

\section{Implication for scholars and practitioners}


Most previous studies published in the top 25 English-language public affairs journals focused on managing governmental organizations. Other areas (e.g., nonprofit management) were largely ignored or received insufficient attention. We believe that these fields demand more scholarly attention in the future. We are not suggesting a comprehensive list here, but we hold that at a minimum the following eight fields may be fruitful for generating pertinent publications:

1) Nonprofit management

2) Emergency management

3) Global comparative public administration (including the PRC)

4) Inter-governmental relations

5) Public-private partnership (PPP)

6) Environmental protection

7) Climate change

8) Performance measurement and improvement

For example, while an administration is in transition from communism to the market economy, not every citizen will be satisfied with the type and quality of the public services government provides. Governments must depend increasingly on the nonprofit sector or citizens to coproduce public services ( $\mathrm{Li}, 2020$ ). Therefore, it is important to understand the implications of the critical role of nonprofit organizations in meeting societal needs.

\section{Conclusion and future prospects}

This short paper highlights the importance and relevance of studying Chinese public administration. As China becomes an increasingly important member in the global village, more attention should be paid to the study of Chinese public administration. On the one hand, many studies will continually focus on studying Chinese public administration itself, and on the other hand comparative study between China and other countries will likely flourish as well.

In his study of Chinese public administration, Lan (2019) provided a list of hot issue areas: public issues of public management (public management theory), reform of administrative approval systems, reform of public institutions, reform of pension insurance systems, emergency management, medical policies, equalization of public services, community issues, community development and services, social conflict (neighborhood issues), performance management, regional cooperation, land policy, urban-rural coordination, fiscal and taxation system reform, food safety, budget reform, government purchases, public ethics, modern governance systems, e-government and big data, etc. 
Other scholars have indicated future paths for the development of Chinese public administration. As a typical interdisciplinary and comprehensively applied academic field, public administration needs to utilize knowledge and methods of neighboring disciplines. The innovation and development of China's public administration research must do the same. In particular, Chinese public administration must actively introduce scientific research methods and paradigms; it must integrate new knowledge, new technologies, and new methods from the fields of cognitive science, neuropsychology, quantum theory, prediction, information and communication technology, intelligent technology, and virtual technology; these initiatives will undoubtedly and innovatively contribute to developing the discipline of Chinese public administration (Chen, 2019).

The debate over the politics-public administration dichotomy is never outdated. Public administration is closely related to, or intertwined with, politics. Chinese public administration is not an exception. Recently, Prof. Puqu Wang, Dean of the National Governance Institute of Peking University, delivered a keynote speech at Oxford University. He pointed out that the modernization of the national governance system under the centralized leadership of the Communist Party of China has offered a reform direction for the modernization of the national governance system with Chinese characteristics since the 18th National Congress of the Communist Party of China (Liu, 2019). Wang's speech reflects the recent emphasis of national governance systems and the modernization of governance capabilities by the top leaders of China.

One major question in public administration is what its main focal points should be. Concerns about the future of the nation and human destiny, and responding to the challenges of the times, are the most pressing issues facing public administration. Change and innovation are the only way to solve emerging problems. The key to change and innovation is the transformation of the internal revolution, which means developing our objective consciousness. The internal revolution requires us to rethink the essential relationships that matter to human destiny (Zhang, 2019).

\section{References}

Chen, Z.(2019). Historic Mission of Public Administration Research. Renmin Ri Bao. November 25, 2019. Online: access December 28, 2019.

Holzer, M., \& Kasymova, J. (2012). Restating the Relevance of Comparative Public Administration. Public Administration Review, 72(1), 162-164.

IMF. (2019). World Economic Outlook Database. Online: access January 8, 2020.

https://www.imf.org/external/pubs/ft/weo/2019/02/weodata/index.aspx

Jreisat, J. E. (2005). Comparative Public Administration is Back in, Prudently. Public Administration Review, 65(2), 231-242.

Kim, M., Li, H., Holzer, M., \& Zhang, M. (2019). Public Administration Research in Mainland China: A Systematic Review of Chinese Public Administration in English Language Journals (1996-2016). International Journal Of Public Administration, 49(2), 753-764. https://doi.org/10.1080/01900692.2018.1506936

Kim, M.-H., Li, H., Holzer, M., \& Zhang, M. (2019). Public Administration Research in Mainland China. In A. Farazmand (Ed.), Global Encyclopedia of Public Administration, Pub- 
lic Policy, and Governance. Springer International Publishing. https://doi.org/10.1007/9783-319-31816-5_3717-1

Lan, Z. (2019). Public Management Online: access December 27, 2019.

https://mp.weixin.qq.com/s/4iT74xmbatGxITWU68PO_g

Li, H. (2020). Communication for coproduction: A systematic review and research agenda. Journal of Chinese Governance. 5(1), 110-135. https://doi.org/10.1080/23812346.2019.1695711 Liu, S. (2019). Dean of National Institute of Governance Wang Puqu was invited to speak at Oxford University. Nov 13, 2019. Online: access December 24, 2019.

https://mp.weixin.qq.com/s/TN_VwrYxMSdsrSY8zGd5gw

National MPA Education Steering Committee. (2020).Universities and Colleges. Online: access January 14, 2020. http://www.mpa.org.cn/school-list

Roberts, J. M. (1993). A short history of the world. Oxford University Press, USA.

Zhang, C. (2019). The Transformation of Consciousness and the Internal Revolution - a Dialogue on the Big Issues of Public Administration in Our Time. Online: access December 25, 2019. https://mp.weixin.qq.com/s/ck7gYnhtjIEL4BnWtnOaTg

Zhang, M. (2006). Administration reforms in China: Globalization or Localization? In Ali Farazmand \& Jack Pinkowski (Eds), Handbook of Globalization, Governance, and Public Administration, (pp.553-584). Marcel Dekker. 